\title{
Correction to: Effects of large-scale wind on the Kuroshio path south of Japan in a 60-year historical OGCM simulation
}

\author{
Hiroyuki Tsujino $^{1} \cdot$ Shiro Nishikawa ${ }^{1,2,3} \cdot$ Kei Sakamoto $^{1} \cdot$ Norihisa Usui $^{1} \cdot$ Hideyuki Nakano $^{1} \cdot$ Goro Yamanaka $^{1}$
}

Published online: 11 September 2018

๑) Springer-Verlag GmbH Germany, part of Springer Nature 2018

\section{Correction to: Clim Dyn (2013) 41: 2287-2318 \\ https://doi.org/10.1007/s00382-012-1641-4}

In the original publication of the article, Fig. 18 was published incorrectly. The correct version of Fig. 18 is provided here.
The original article can be found online at https://doi.org/10.1007/ s00382-012-1641-4.

Hiroyuki Tsujino

htsujino@mri-jma.go.jp

1 Meteorological Research Institute, 1-1 Nagamine, Tsukuba, Ibaraki 305-0052, Japan

2 Atmosphere and Ocean Research Institute, University of Tokyo, Kashiwa, Chiba 277-8568, Japan

3 Present Address: Data Research Center for Marine-Earth Sciences, Japan Agency for Marine-Earth Science and Technology, Yokohama, Kanagawa 236-0001, Japan (a)

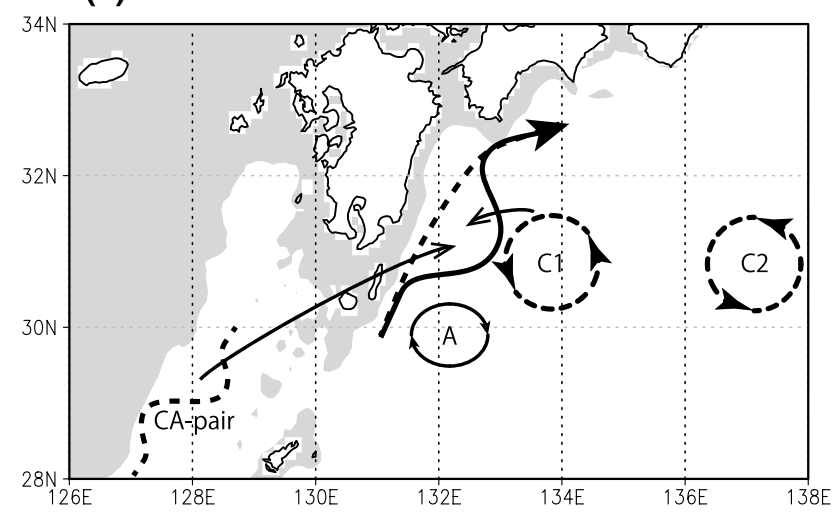

(b)

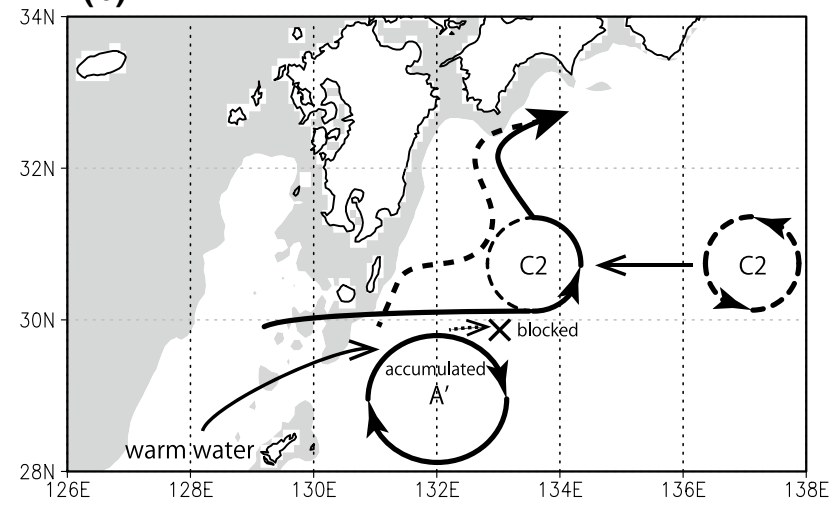

Fig. 18 Schematic of the trigger meander formation. a Formation of a small meander. A large amplitude small meander is formed by the merger of the cyclonic part of a cyclonic-anticyclonic pair (CA-pair) from the East China Sea, which is induced by a positive SSHA meeting the western boundary in the further upstream, and the cyclonic eddy that migrates westward along the outskirts of the recirculation gyre (C1). b Enhancement of a small meander. The existing small meander is enhanced by the second merger with the cyclonic eddy from the east (C2). During this merger, the anticyclonic eddy south of the cyclonic eddy is blocked by the merging cyclonic eddies and warm Kuroshio water from upstream is accumulated. The formation of a large anticyclonic eddy is important for a meander to evolve eventually into a LM through baroclinic instability 